\title{
Seriam eles indomáveis
} rara sar̃̄o* protagonistas?

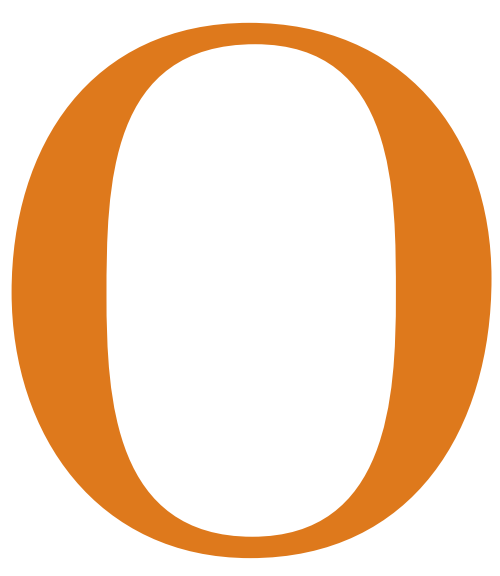

s alunos de quinta a oitava séries do ensino fundamental já há muito tempo vêm sendo considerados “indomáveis" pela escola, por estarem numa idade apontada como difícil e ingrata para o trabalho do professor.

E por quê?

- Trata-se de um problema que tem a ver apenas com os alunos ou também com o trabalho coletivo e educativo da escola?

- Quais são as grandes questões que os educadores dessas séries têm se colocado?

Podemos mapear algumas diferenças, ocorridas nos últimos anos, que contribuem para que essas séries estejam sendo objeto de estudo e preocupação mais intensas.

Nosso ponto de partida é, de um lado, a escuta, o acompanhamento e a reflexão junto a grupos de educadores e de psicólogos que tematizam suas práticas em instituições escolares da rede pública; de outro, atuações pontuais em algumas escolas de ensino fundamental.

Uma questão que tem chamado a atenção dos educadores na escola, bem mais do que antes, é a função da família, ou melhor, segundo alguns professores, as falhas das famílias em sua tarefa de educar e, por conseqüência, a sobrecarga que significa a delegação dessa função para a escola.

Seria então a educação escolar a continuidade da educação doméstica? Ou será que esta observação ou “queixa" estaria revelando a dificuldade da escola em encontrar suas próprias respostas aos inúmeros desafios que se têm apresentado?

Podemos afirmar que ambas as instituições - família e escola - encontram-se fragilizadas e assustadas com as questões que as crianças e adolescentes têm colocado para a sociedade, o que faz com que proliferem as cobranças e acusações recíprocas.

Vejamos: família e escola têm responsabilidades na educação das crianças e adolescentes, mas são respon-

* Yara SaYão é psicóloga do Serviço de Psicologia Escolar da USP. 
sabilidades bem diferentes. Na família, o convívio é intensamente atravessado pela questão afetiva: carinho, lembranças, amor, raiva, inveja, afinidades, disputas, rancores, preferências etc. É muito difícil imaginar (talvez impossível mesmo) a convivência entre familiares que não seja marcada por vários desses sentimentos.

Dada a natureza da instituição familiar, por melhor que ela seja, há uma clara limitação para a experiência do convívio com os diferentes, ou seja, com os “outros", com quem não há uma ligação afetiva imediata.

E a escola? Para além de sua função principal, que é a de dar acesso ao conhecimento de forma sistematizada, é neste privilegiado espaço que a criança, ao conhecer e vivenciar o papel de aluno, pode também experimentar o contato social com os diferentes, essencial para o exercício da cidadania.

Isso confere, à escola, uma grande responsabilidade no ensino das questões relativas aos valores indispensáveis à vida democrática, entendendo-se aqui que a democracia é importante não apenas como regime político, mas também como forma de sociabilidade. E o respeito às diferenças é um desses valores essenciais. Conhecemos vários exemplos históricos de intolerância e discriminação das diferenças e seus efeitos nefastos em todos os níveis da vida pública e privada.

Então, é na escola - espaço público - que a criança, agora aluno ou aluna, poderá aprender a respeitar o outro, mesmo que esse outro nada represente para ela afetivamente. Também outros valores, como justiça e solidariedade, serão aprendidos pelas crianças de forma diversa daqueles ensinados pela família em relação a estas mesmas questões, uma vez que, na família, esse aprendizado sempre ocorre permeado pelos afetos, podendo até gerar, como efeito, em situações peculiares, aprendizados equivocados. Por exemplo: numa situação de conflito na escola, a defesa de um aluno aos irmãos/parentes/amigos quase sempre se sobrepõe ao julgamento moral de suas atitudes.

\section{Tratamentos diferenciados e circunstanciais}

\section{Ao experimentar cotidianamente situações em que a}

igualdade de direitos é proposta e os adultos a respeitam, as crianças e adolescentes poderão descobrir as importantes dimensões do relacionamento social que possibilitam o estabelecimento da noção de alteridade, assim como o aprendizado dos valores que viabilizam a construção e a convivência numa sociedade democrática.

\section{Escola: é neste privilegiado espaco que a crianca, ao conhecer e vivenciar o papel de aluno, pode também experimentar o contato social com os diferentes, essencial para o exercício da cidadania.}

Isso poderá acontecer, por exemplo, nos simples e antigos rituais existentes em quase todas as salas de aula: o professor irá atender, pela ordem, quem primeiro levantar a mão, independente de quem seja. Na condição de alunos, todos têm os mesmos direitos, e a escola precisa ter regras para que cada um aprenda a compartilhar o espaço coletivo com seus semelhantes.

Isso chama a atenção para o conceito da eqüidade, pois o fato de todos os alunos terem os mesmos direitos não significa que sejam iguais ou que devam ser tratados da mesma forma. As diferenças entre os alunos (de gênero, condição social, conhecimentos prévios, grau/ modalidade de aprendizagem, comportamento etc.) podem justamente indicar a necessidade de tratamentos diferenciados e circunstanciais para se ter, como meta, a verdadeira igualdade no acesso a todos os direitos - e esta é uma questão fundamental para se analisar a questão da inclusão.

Temos então revelada a responsabilidade diferenciada da escola em relação à família: não se trata, portanto, de dar conta, na escola, do que a família não quer ou não consegue fazer, e sim de trabalhar em situações e experiências fundamentalmente distintas das que a criança pode conhecer e aprender nas situações domésticas, no convívio familiar.

Esse reconhecimento indica que a escola deve dar ênfase a si mesma e a seus processos. É na organização do cotidiano escolar, nas decisões tomadas pelos educadores e nas diretrizes que a escola escolhe para seguir que reside a responsabilidade de educar para o exercício pleno da cidadania. E isso ocorre independentemente do tipo e qualidade de educação e de valores que cada família dá a seus filhos e que, muitas vezes, são objeto de um severo julgamento/crítica da parte dos educadores na escola.

Atualmente, muitas escolas têm se esforçado bastante para trabalhar com as famílias, baseadas na crença de que uma atuação mais rigorosa delas com seus filhos poderia diminuir os problemas de comportamento dos alunos na 
escola. Isso, por vezes, ocorre em detrimento de discussão coletiva mais aprofundada sobre as próprias práticas educativas adotadas na escola. A expressão "parceria escola-família" tem sido largamente utilizada de forma pouco criteriosa, principalmente pelo fato de não se ter clareza do papel diferenciado de cada uma delas, e isso deve ser questionado, discutido e analisado por todos na equipe escolar. Um grande risco que os educadores escolares correm ao dar prioridade à autoridade da família é o de enfraquecimento da sua autoridade e dos demais educadores no interior da própria escola.

\section{Pré-adolescentes}

\section{Outro aspecto, referente ao que acontece na escola, que} tem chamado muito a atenção dos educadores é o comportamento dos agora denominados "pré-adolescentes". Se, tempos atrás, a preocupação maior dos professores era apenas com os adolescentes, hoje eles ficam completamente espantados com a capacidade de enfrentamento demonstrada por crianças de dez ou 11 anos e também com as manifestações ousadas de sexualidade, principalmente das meninas. 0 que está acontecendo?

Ocorre que as transformações físicas/emocionais/sociais da puberdade agora se dão num contexto muito diverso dos cenários anteriores: vemos, atualmente, um verdadeiro culto à juventude, o que possivelmente faz com que essa faixa etária seja alvo de muita atenção, curiosidade, idolatria, apreensão, medo.

Não deve ser fácil entrar numa fase da qual, aparentemente, até muitos adultos não querem sair. Há certa inversão nos vetores que anteriormente apontavam para o mundo adulto como sede das maiores potencialidades: intelectuais, sociais, de sucesso profissional e pessoal etc.

Assistimos a uma hipervalorização da juventude em todos os seus âmbitos, paradoxalmente ao tipo de abordagem que se faz aos jovens: ainda estão presentes, no campo educacional, as antigas concepções de adolescência como etapa de transição entre duas fases mais definidas da vida - a infância e a idade adulta. Isso, possivelmente, tem relação com parte das tensões que os alunos e alunas de quinta a oitavas séries vivem, e que eles próprios têm dificuldade em nomear e/ou expressar diretamente.

Podemos entender a adolescência, nomeada de "idade difícil”, também como o ingresso num espaço etário “incongruente": é muito boa e desejável, mas, ao mesmo tempo, desvalorizada. Isso porque os jovens são mais co- mumente tomados como objeto - da ação educativa, da propaganda, da valorização estética, do discurso adulto etc. - , do que como sujeitos.

Será que as inúmeras atitudes radicais desses alunos - crianças e adolescentes - significam um pedido de ajuda aos educadores, para que eles os percebam como sujeitos que estão convivendo com grandes transformações tanto internas quanto externas e que, na experimentação típica desses momentos, não estão podendo contar com eixos norteadores seguros, em termos de valores?

Será que, em meio a tantas incertezas, os adultos estão conseguindo exercer a autoridade necessária para que esses alunos possam aprender/descobrir/inventar novas formas de viver e de conviver numa sociedade tão contraditória? Muitos adultos enfrentam grandes dificuldades para discriminar questões que são da esfera pública das que dizem respeito à vida privada, fato esse que se torna particularmente difícil para os alunos, que ainda pouco sabem das diferenças e semelhanças entre essas esferas.

É certo que o grupo de iguais, a turma dos jovens, passa a desempenhar intenso papel na adolescência, mas é inegável a importância da interlocução das crianças e dos adolescentes com os adultos que lhes são significativos para o enfrentamento dos difíceis momentos de transição. E não podemos esquecer que a família, palco de muitas tensões no momento da adolescência, nem sempre pode oferecer a interlocução adequada aos jovens.

Os educadores da escola, nesse momento, têm mais isenção para ajudar os alunos a pensar seus próprios valores, opiniões, atitudes e ações. E tudo isso pode ocorrer nos momentos/espaços em que se processam as aprendizagens dos conteúdos, uma vez que essas questões se relacionam com a postura do professor/educador no trato de qualquer questão dentro da escola. É fundamental que os professores articulem o conteúdo de sua área específica (definido no projeto coletivo da escola) com as questões ligadas ao comportamento e às preocupações dos alunos.

Para esse tipo de atividade didática, há que se cuidar também da competência técnica do professor em sua área específica de conhecimento, pois a postura de autoridade relaciona-se com o conhecimento teórico/técnico necessário para o exercício de sua função.

A fundamentação apresentada pelos Parâmetros Curriculares Nacionais - PCN - para os chamados Temas Transversais indica tanto a importância quanto as possibilidades de trabalho pedagógico com as relevantes questões 
sociais destacadamente ligadas aos valores e à abordagem, em especial, do tema Ética, que traz importantes elementos para o trabalho da equipe escolar no que diz respeito às questões que estamos apresentando.

\section{Descobertas de amor, amizade, medo e solidão.}

\section{Tendo imensas transformações sociais como pano de} fundo, para cada adolescente, há o momento da descoberta pessoal da sexualidade em suas formas mais relacionais. Muitas vezes, a sala de aula, e mesmo a escola, parece se espelhar no belo poema de Drummond:

João amava Teresa que amava Raimundo

que amava Maria que amava Joaquim que amava Lili que não amava ninguém...

As primeiras experimentações amorosas e também de escolhas de amizade vão se dar de forma um tanto espetacular numa sociedade que também privilegia a imagem externa e o espetáculo (vide o enorme aumento de revistas/livros que abordam as "celebridades").

Antes ainda de saber o que exatamente buscam, os adolescentes já são levados a se preocupar com o que "parecem ser" aos olhos dos outros, e isso pode atrapaIhar bastante suas escolhas e experimentações, assim como o aprendizado resultante disso. Fazer parte de uma turma "da pesada", porém conhecida, falada e comentada por todos, pode ser bem atraente para um adolescente que se sente invisível para os outros.

Tomar a iniciativa, por vezes de forma agressiva, intimidadora e desrespeitosa, de convidar os garotos para um relacionamento mais íntimo, mesmo que breve, tem sido uma prática muito usual de meninas por volta dos 11 anos. Esse tipo de atitude surpreende muitos os educadores, já acostumados a lidar com manifestações de sexualidade na escola, pois inverte o que antes sempre acontecia: agora são os meninos dessa idade a demandarem o cuidado e até a proteção dos educadores.

A ousadia das meninas, por outro lado, pode também ser uma estratégia para destacar uma identidade feminina forte, em contraponto à posição de maior submissão atribuída historicamente às mulheres.

Nos últimos anos, há um notável aumento da gravidez na adolescência, justamente na faixa que vai de dez a 14 anos. 0 que isso pode representar em termos sociais? Pela legislação brasileira em vigor, o relaciona- mento sexual com garotas de menos de 12 anos é uma violência, já que, pelo Estatuto da Criança e do Adolescente, elas são consideradas crianças.

E na faixa de 12 a 14 anos? Sem dúvida, é uma questão bastante complexa, mas supomos que, devido à falta de perspectivas de inserção social e ao desejo de gerar algo novo no meio em que vivem, a capacidade produtiva de muitas meninas se volta para o próprio corpo, tomado como possibilidade plausível de criação de um fato realmente inédito, que mude a sua relação com a família e com todo o meio em que vive, proporcionandoIhes uma posição social distinta da que ocupam hoje. Além disso, a vivência de sua sexualidade também é associada a uma experiência vista como prazerosa. Enfim, é a possibilidade de deixar sua marca no mundo, e este é o grande desejo dos jovens.

A novidade é que muitos meninos, antes muito temerosos e arredios diante da paternidade, atualmente, demonstram interesse e até orgulho em "assumir". Percebe-se que a idéia e os sentimentos associados à gravidez são um tanto desconectados de todas as responsabilidades inerentes aos cuidados de um bebê e que a atitude dos adolescentes em relação à paternidade precisa ser confrontada com a capacidade de decisão e experiência possiveis para quem hoje tem 14 ou 15 anos.

Isso pode nos fazer pensar sobre o parco campo de experimentações, aprendizados e produções concretas que a sociedade, em geral, e a escola, em especial, têm oferecido aos jovens, talvez ele seja insuficiente para acoIher e dar vazão à energia criativa dos adolescentes.

Um fenômeno preocupante tem sido relatado por muitos educadores: nota-se o aumento de transtornos depressivos e/ou ligados às atitudes destrutivas nos alunos dessas séries. Em muitos acontecimentos dessa natureza, as conversas posteriores com os alunos que protagonizam essas cenas revelam sua estranheza diante de atos que praticaram e/ou revelam verdadeiro desconhecimento de possíveis desencadeadores pessoais para tais episódios.

Há relatos de sentimentos como o de solidão e de dificuldade de ter/manter as amizades. Para muitos adolescentes, não há diferença entre amizade e cumplicidade, o que revela a necessidade de se conhecer/discutir mais as relações sociais na escola (nos âmbitos públicos e privados) para melhor conhecer e discriminar questões tão importantes como essas. 


\section{Trabalhos escolares que ajudem o aluno a decodificar/ \\ analisar/compreender a linguagem da midia e da Internet são fundamentais para diminuir o processo de alienação a que os jovens são submetidos pelos meios de comunicacão atuais.}

Autoridade, rebeldia e limites

\section{Em alguns levantamentos informais realizados por pro-} fessores junto a seus alunos, o principal problema é a bagunça na sala de aula. Esse problema é apontado tanto pelos professores quanto pelos principais atores das "badernas". Há um reconhecimento dos alunos da importância de o professor ocupar o lugar de autoridade no desempenho de sua tarefa, o que não quer dizer que eles não sintam, ao mesmo tempo, desejo de desafiar o professor, provocá-lo e desviá-lo de sua função.

É típico da adolescência o aumento da capacidade crítica sem que se tenha ainda desenvolvido e canalizado, de forma expressiva, a capacidade de construir e produzir. 0 desenvolvimento dessas capacidades se faz com o auxílio do adulto, orientando e coordenando as atividades, por exemplo, nos trabalhos por projetos, nos quais os alunos encontram maiores possibilidades de eleição/ experimentação de novas formas de conviver, de aprender e de realizar tarefas em grupo, a partir de temáticas que povoem seus cotidianos.

Há ainda muita preocupação com o crescimento da influência dos meios de comunicação nos alunos, especialmente nas séries da segunda etapa do ensino fundamental. Sem debate e sem a presença do educador, são poucas as possibilidades de os alunos formarem opinião sobre o que vêem. Eles sentem dificuldade em se situar e se posicionar diante de tanta diversidade e mesmo disparidade, tanto em relação aos fatos divulgados quanto às suas versões e interpretações.

Também é função da escola auxiliar o aluno a "ler" as imagens às quais está diariamente exposto. É interessante não esquecer que boa parte das informações que os alunos têm, inclusive sobre Ciências, vem de fontes como a televisão e a Internet e entender que há intenções nem sempre explícitas depositadas na linguagem da propaganda, lembrando, por exemplo, que boa parte delas se destina aos jovens.

\section{A escola pode mudar esse quadro}

\section{Se a escola e os educadores puderem fazer apostas no} sentido de possibilitar aos alunos maior capacidade crítica e, portanto, atitudes menos passivas diante dos perturbadores processos sociais, talvez possamos ver mudanças significativas no quadro atual. Trabalhos escolares que ajudem o aluno a decodificar/analisar/compreender essa linguagem são fundamentais para diminuir o processo de alienação a que os jovens são submetidos pelos meios de comunicação atuais.

Todos esses aspectos do comportamento são importantes para demonstrar que é impossível tomarmos os alunos como preocupação sem considerarmos a sociedade em que estão imersos e que condiciona boa parte de todos os acontecimentos nos quais eles são os protagonistas, por vezes sem serem sujeitos de sua ação.

É possível que parte da violência que ocorre hoje nas escolas possa ser compreendida como contestação e resposta à exclusão. Ao mesmo tempo, atos violentos não seriam também um tipo de resposta "enviesada" que denuncia o fato de que os alunos não se sentem levados a sério, por seus educadores, como sujeitos da ação educativa?

Será que a escola não tende a tratá-los como pessoas que precisam estudar para ser alguém no futuro e não no presente? Será que podemos compreender os atos violentos como desesperados pedidos da presença de adultos significativos - seus educadores - junto a eles, alunos, em momentos em que ainda não sabem discriminar valores, organizar-se como grupo autônomo e responder pelo que fazem?

É importante lembrarmos que os alunos de quinta a oitava séries processam o conhecimento ao mesmo tempo em que processam, subjetivamente, novas e múltiplas possibilidades de ser e de enfrentar o mundo, o que implica demandas diferenciadas.

Referências

CUNHA, Marcus V.A desqualificação da família para educar. Cadernos de Pesquisa da Fundação Carlos Chagas, n. 102, p. 46-64, nov. 1997.

GUARÁ, Isa Maria F. Rosa. Modernidade, adolescência e cidadania. In: VV.AA. Cidadania e subjetividade. Ed. Imaginário, 1997.

MASAGÃO, Vera. Palestra proferida no CENPEC (texto publicado nesta edição). CAMPOS, Maria Malta. A importância das relações humanas na escola (nesta edição).

Relatório de pesquisa: A educação no Ciclo II do Ensino Fundamental (2006), elaborado pelo CENPEC (nesta edição). 